\title{
A New Control Technique for Damping Low Frequency Oscillations
}

\author{
Sangu Ravindra ${ }^{1}$, Dr.V.C.Veera Reddy ${ }^{2}$, Dr.S.Sivanagaraju ${ }^{3}$ \\ ${ }^{I}$ Associate Professor, Department of EEE, QISCET, Ongole, \\ ${ }^{2}$ Professor, Department of EEE, S.V.University, Tirupathi, \\ ${ }^{3}$ Associate Professor, Department of EEE, JNTUK, Kakinada.
}

\begin{abstract}
Low Frequency Oscillations (LFO) are a frequent adverse phenomenon which increase the risk of instability for the power system and thus reduce the total and availability transfer capability (TTC and ATC).LFO occur in power systems because of lack of the damping torque in order to dominance to power system disturbances as change in mechanical input power. In the recent past Power System Stabilizer (PSS) was used to damp LFO. FACTs devices, such as Unified Power Flow Controller (UPFC), can control power flow and increase transient stability. So UPFC may be used to damp LFO instead of PSS. UPFC damps LFO through direct control of voltage and power. In this research the linearized model of synchronous machine (Heffron-Philips) connected to infinite bus (Single Machine-Infinite Bus: SMIB) with UPFC is used and also in order to damp LFO, adaptive ANN damping controller for UPFC is designed and simulated. Simulation is performed for various types of loads and for different disturbances. Simulation results demonstrate that the developed ANN damping controller would be more effective in damping electromechanical oscillations in comparison with the conventional lead-lag controller.
\end{abstract}

Keywords: - Low Frequency Oscillations (LFO), Unified Power Flow Controller (UPFC), Single MachineInfinite Bus (SMIB) power system, Artificial Neural Network (ANN) damping controller.

\section{INTRODUCTION}

The Benefits of Flexible AC Transmission Systems (FACTs) usages to improve power systems stability are well known [1], [2]. The growth of the demand for electrical energy leads to loading the transmission system near their limits. Thus, the occurrence of the LFO has increased. FACTs controllers has capability to control network conditions quickly and this feature of FACTs can be used to improve power system stability. The UPFC is a FACTS device that can be used to the LFO. The primarily use of UPFC is to control the power flow in power systems. The UPFC consists of two voltage source converters (VSC) each of them has two control parameters namely $m e, \delta e, m b$ and $\delta b$ [3]. The UPFC used for power flow control, enhancement of transient stability, mitigation of system oscillations and voltage regulation [3]. A comprehensive and systematic approach for mathematical modeling of UPFC for steady-state and small signal (linearized) dynamic studies has been proposed in [4-7]. The other modified linearized Heffron-Philips model of a power system installed with UPFC is presented in [8] and [9]. For systems which are without power system stabilizer (PSS), excellent damping can be achieved via proper controller design for UPFC parameters. By designing a suitable UPFC controller, an effective damping can be achieved. It is usual that Heffron-Philips model is used in power system to study small signal stability. This model has been used for many years providing reliable results [10].

In this study, Applying artificial neural networks has many advantages such as the ability of adapting to changes, fault tolerance capability, recovery capability, High-speed processing because of parallel processing and ability to build a DSP chip with VLSI Technology. Matlab toolbox is used as a computing tool to implement the ANN. To show performance of the designed adaptive artificial neural network controller, a conventional lead-lag controller that is designed in [11] is used and the simulation results for the power system including these two controllers are compared with each other.

\section{POWER SYSTEM MODELING WITH UPFC}

UPFC is one of the famous FACTs devices that is used to improve power system stability. Fig.1 shows a single machine-infinite-bus (SMIB) system (Heffron-Philips model of a power system installed with UPFC) with UPFC. It is assumed that the UPFC performance is based on pulse width modulation (PWM) converters. In figure $1 \mathrm{me}, \mathrm{mb}$ and $\delta e, \delta b$ are the amplitude modulation ratio and phase angle of the reference voltage of each voltage source converter respectively. These values are the input control signals of the UPFC. 


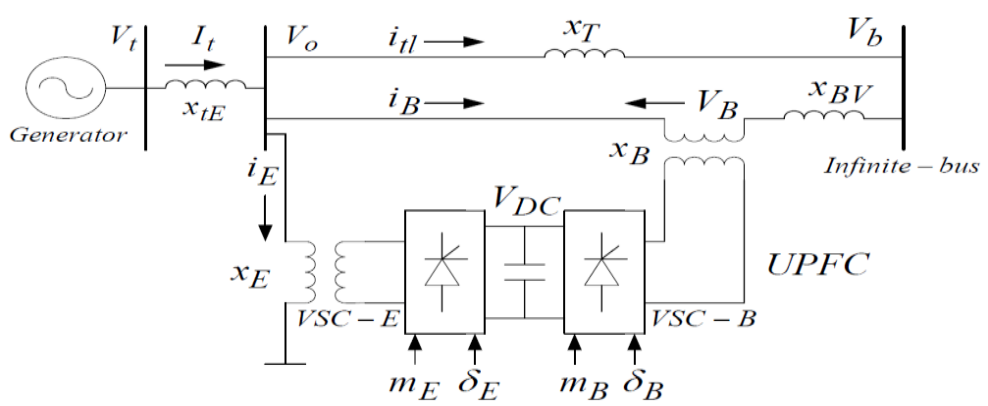

Fig 1: Heffron-Philips model of a power system installed with UPFC

As it mentioned previously, a linearized model of the power system is used in dynamic studies of power system. In order to consider the effect of UPFC in damping of LFO, the dynamic model of the UPFC is employed; In this model the resistance and transient of the transformers of the UPFC can be ignored.

The system's dynamic relations are expressed as follows:

$$
\begin{aligned}
& \bar{\delta}=\omega_{o} \Delta \omega \\
& \bar{\omega}=\left(P_{m}-P_{e}-D \omega\right) / M \\
& \bar{E}^{\prime} q=\left(-E_{q}+E_{f d}\right) / T_{d o}^{\prime} \\
& \bar{E}_{f d}=-\frac{1}{T_{A}} E_{f d}+\frac{K_{A}}{T_{A}}\left(v_{t o}-v_{t}\right)
\end{aligned}
$$

There exit several models for UPFC depending on several study cases.

The following equation describe the dynamic behavior of UPFC :

$$
\begin{aligned}
& {\left[\begin{array}{l}
v_{E t d} \\
v_{E t q}
\end{array}\right]=\left[\begin{array}{cc}
0 & -x_{E} \\
x_{E} & 0
\end{array}\right]\left[\begin{array}{c}
i_{E d} \\
i_{E q}
\end{array}\right]+\left[\begin{array}{l}
\frac{m_{E} v_{d c} \cos \delta_{E}}{2} \\
\frac{m_{E} v_{d c} \sin \delta_{E}}{2}
\end{array}\right]} \\
& {\left[\begin{array}{c}
v_{B t d} \\
v_{B t q}
\end{array}\right]=\left[\begin{array}{cc}
0 & -x_{B} \\
x_{B} & 0
\end{array}\right]\left[\begin{array}{c}
i_{B d} \\
i_{B q}
\end{array}\right]+\left[\begin{array}{l}
\frac{m_{B} v_{d c} \cos \delta_{B}}{2} \\
\frac{m_{B} v_{d c} \sin \delta_{B}}{2}
\end{array}\right]} \\
& \frac{d v_{d c}}{d t}=\frac{3 m_{E}}{4 C_{d c}}\left[\begin{array}{ll}
\cos \delta_{E} & \sin \delta_{E}
\end{array}\right]\left[\begin{array}{c}
i_{E d} \\
i_{E q}
\end{array}\right]+\frac{3 m_{B}}{4 C_{d c}}\left[\begin{array}{ll}
\cos \delta_{B} & \sin \delta_{B}
\end{array}\right]\left[\begin{array}{c}
i_{B d} \\
i_{B q}
\end{array}\right]
\end{aligned}
$$

By combining the above linear dynamic equations, The state equations expressed as follows:

$\dot{\mathrm{X}}=\mathrm{AX}+\mathrm{BU}$

Where the matrixces

$$
X=\left[\begin{array}{l}
\Delta \delta \\
\Delta \omega \\
\Delta E_{Q}^{\prime} \\
\Delta E_{f d} \\
\Delta v_{d c}
\end{array}\right]
$$




$$
U=\left[\begin{array}{c}
\Delta m_{E} \\
\Delta \delta_{E} \\
\Delta m_{B} \\
\Delta \delta_{B}
\end{array}\right]
$$

Where $\Delta \mathrm{m}_{\mathrm{E}}, \Delta \delta_{\mathrm{E}}, \Delta \mathrm{m}_{\mathrm{B}}$ and, $\Delta \delta_{\mathrm{B}}$ are the variations of UPFC control parameters considered as the inputs of state space model

$$
\begin{aligned}
A & =\left[\begin{array}{ccccc}
0 & \omega_{o} & 0 & 0 & 0 \\
-\frac{k_{1}}{M} & -\frac{D}{M} & -\frac{k_{2}}{M} & 0 & -\frac{k_{p d}}{M} \\
-\frac{k_{4}}{T_{d 0}^{\prime}} & 0 & -\frac{k_{3}}{T_{d 0}^{\prime}} & \frac{1}{T_{d 0}^{\prime}} & -\frac{k_{q d}}{T_{d 0}^{\prime}} \\
-\frac{k_{A} k_{5}}{T_{A}} & 0 & -\frac{k_{A} k_{6}}{T_{A}} & -\frac{1}{T_{A}} & -\frac{k_{A} k_{v d}}{T_{A}} \\
k_{7} & 0 & k_{8} & 0 & -k_{9}
\end{array}\right] \\
B & =\left[\begin{array}{cccc}
0 & 0 & 0 & 0 \\
-\frac{k_{p e}}{M} & -\frac{k_{p \delta e}}{M} & -\frac{k_{p b}}{M} & -\frac{k_{p \delta b}}{M} \\
-\frac{k_{q e}}{T_{d 0}^{\prime}} & -\frac{k_{q \delta e}}{T_{d 0}^{\prime}} & -\frac{k_{q b}}{T_{d 0}^{\prime}} & -\frac{k_{q \delta b}}{T_{d 0}^{\prime}} \\
-\frac{k_{A} k_{v e}}{T_{A}} & -\frac{k_{A} k_{v \delta e}}{T_{A}} & -\frac{k_{A} k_{v b}}{T_{A}} & -\frac{k_{A} k_{v \delta b}}{T_{A}} \\
k_{c e} & k_{c \delta e} & k_{c b} & k_{c \delta b}
\end{array}\right]
\end{aligned}
$$

The $k$ coefficients are obtained during the Linearization of (1) and (2) around the operating point[6].

\section{DESIGN OF DAMPING CONTROLLERS}

\subsection{Lead-Lag Controller Design}

As mentioned before, in this study two different controllers have been used to damp LFO. The first one is conventional lead-lag controller. It consists of gain block, washout block, lead-lag compensator block. The washout block is considered as a high-pass filter, with the time constant TW. Without this block steady changes in input would modify the output. The value of TW is not critical and may be in the range of 1 to 20 seconds. In this study, the parameters obtained from lead-lag controller design that is presented in [11], were used.

\subsection{Adaptive Artificial neural networks Controller Design}

Before the ANN can be used to adapt the controller gains in real time, it is necessary to determine a proper set of values for the connection weights.The process of reaching the connection weights is normally carried out off-line and is usually referred to as the training process. In the training process, we first compile a set of training patterns and store these training patterns in the training set. Each training pattern comprises a set of input data and the corresponding output data. A training pattern set of training patterns, which cover a wide range of operating conditions, is finally used to train the desired ANN [16]. It should be noted that we use two hidden layers. Main purpose of ANN is used for the reducing the error in the system, for that we are going to use training data method. In this method, we have to give both input values and desired output value for estimating the weight values, in that initial value taken as a random value. The input are $\Delta \delta$ and $\Delta \omega$, desired output is the function of $\mathrm{f} €\left\{\Delta \delta_{\mathrm{b}}, \Delta \delta_{\mathrm{e}}, \Delta \mathrm{m}_{\mathrm{b}}, \Delta \mathrm{m}_{\mathrm{e}}\right\}$.For each input having 20 membership functions and Two rule base is considered.

ANN architecture for a two input sugeno model with two rules is shown in figure2.in which we are using the XOR gate. 


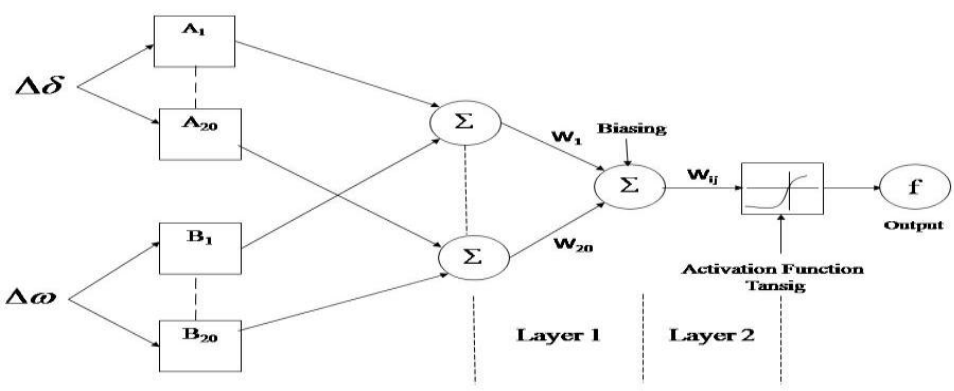

Fig 2: ANN Architecture for a two input sugeno model with two rules

For the training data the error reducing method is the following steps are taken those are

1. Set the Learning Rate Parameter ( $\mathrm{y})$ is greater than the one and error value $\mathrm{E}=0$.

2. First Layer $\mathrm{k}=1$.

3. Calculate the output value $\mathrm{f}_{\mathrm{i}}(\mathrm{n})=\operatorname{tansig}\left(\left\langle\mathrm{W}_{\mathrm{i}}(\mu(\Delta \delta)+\mu(\Delta \omega))\right\rangle\right)+\mathrm{r}$; for $\mathrm{i}=1,2, \ldots 20$.

4. Calculate error $E=E+1 / 2\left\|f-f_{i}(n)\right\|^{2}$.

5. Weights are updated $\mathrm{W}_{\mathrm{i}+1}=\mathrm{W}_{\mathrm{i}}+\mathrm{\eta}\left(\mathrm{f}-\tan \operatorname{sig}\left(\left\langle\mathrm{W}_{\mathrm{i}}(\mu(\Delta \delta)+\mu(\Delta \omega))\right\rangle\right)+\mathrm{r}\right)$; for $\mathrm{i}=1,2 . .20$.

6. Check error $E$ is not zero, then take the layer value as $k=k+1$,

7. Repeat the above process until when the error $\mathrm{E}$ as zero.

From above process we get the desired output function, the output function

$\mathrm{f}=\left(1-\mathrm{e}-\left(\mathrm{W}_{\mathrm{i}}(\mu(\Delta \delta)+\mu(\Delta \omega))+\mathrm{r}\right) /\left(1+\mathrm{e}-\left(\mathrm{W}_{\mathrm{i}}(\mu(\Delta \delta)+\mu(\Delta \omega))+\mathrm{r}\right)\right.\right.$. The range of output function is -1 to +1 .

\section{SIMULATION RESULTS}

In this research, two different cases are studied. In the first case mechanical power and in the second case reference voltage has step change and deviation in $\omega(\Delta \omega)$ and deviation in rotor angle $\delta(\Delta \delta)$ is observed. The parameter values of system are gathered in Appendix. In first case, step change in mechanical input power is studied. Simulations are performed when mechanical input power has $10 \%$ increase $(\Delta \mathrm{Pm}=0.1 \mathrm{pu})$ at $\mathrm{t}=1 \mathrm{~s}$. Simulation results for different types of loads and controllers $\left(\Delta \mathrm{m}_{\mathrm{E}}, \Delta \delta_{\mathrm{E}}, \Delta m_{\mathrm{B}}, \Delta \delta_{\mathrm{B}}\right)$ and step change in mechanical input power are shown in figures 3 to 7 .

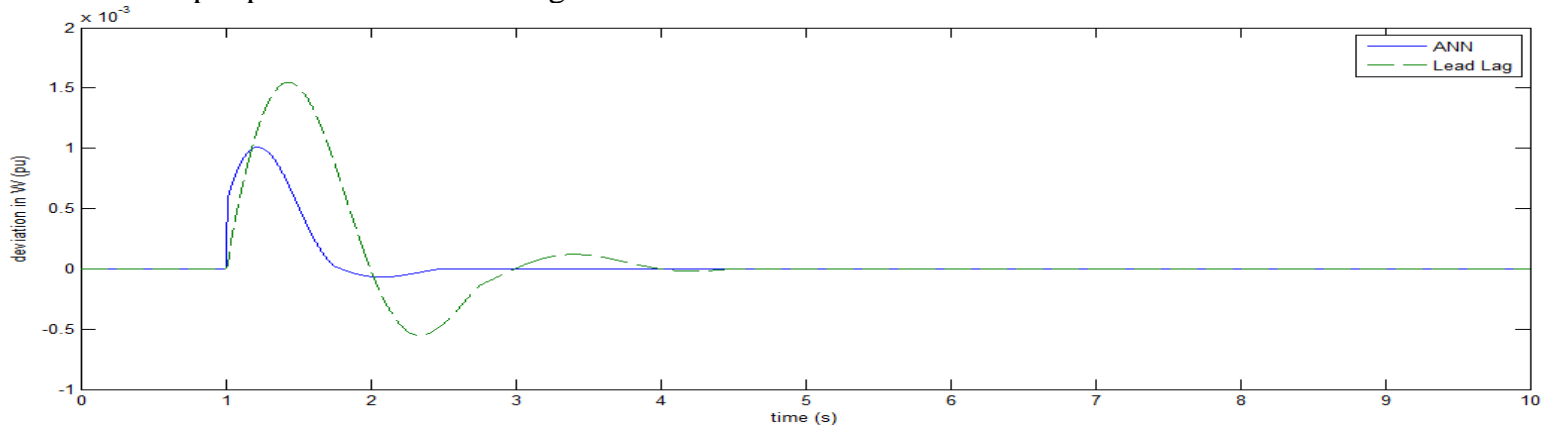

Fig 3: Angular velocity deviation during step change in mechanical input power for nominal load $\left(m_{e}\right.$ Controller $)$

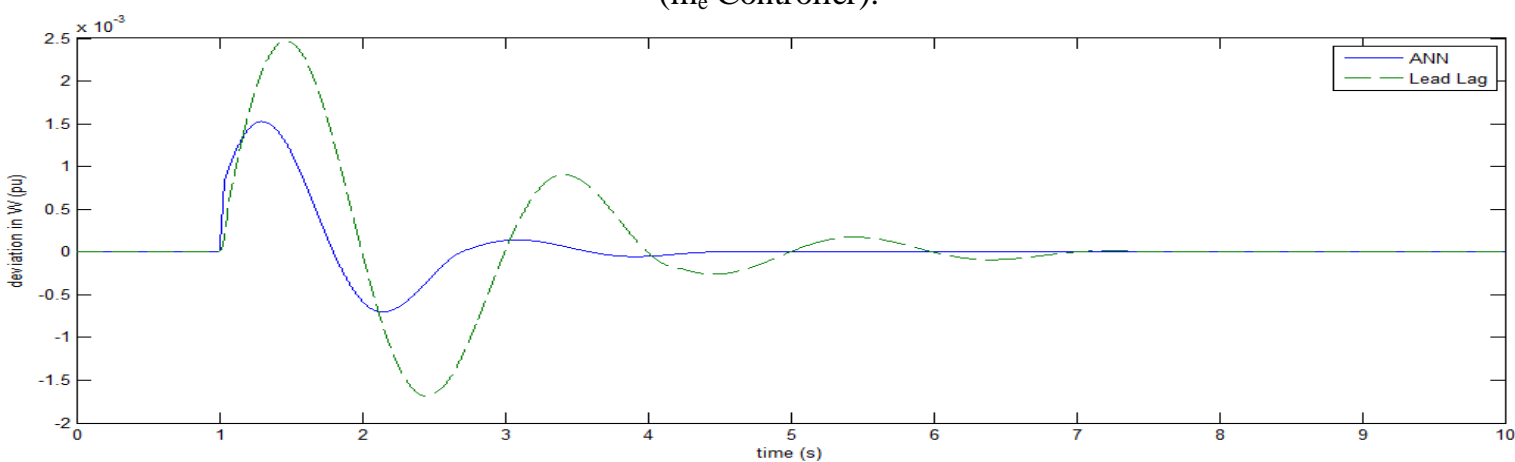

Fig 4: Angular velocity deviation during step change in mechanical input power for light load ( $\mathrm{m}_{\mathrm{e}}$ Controller). 


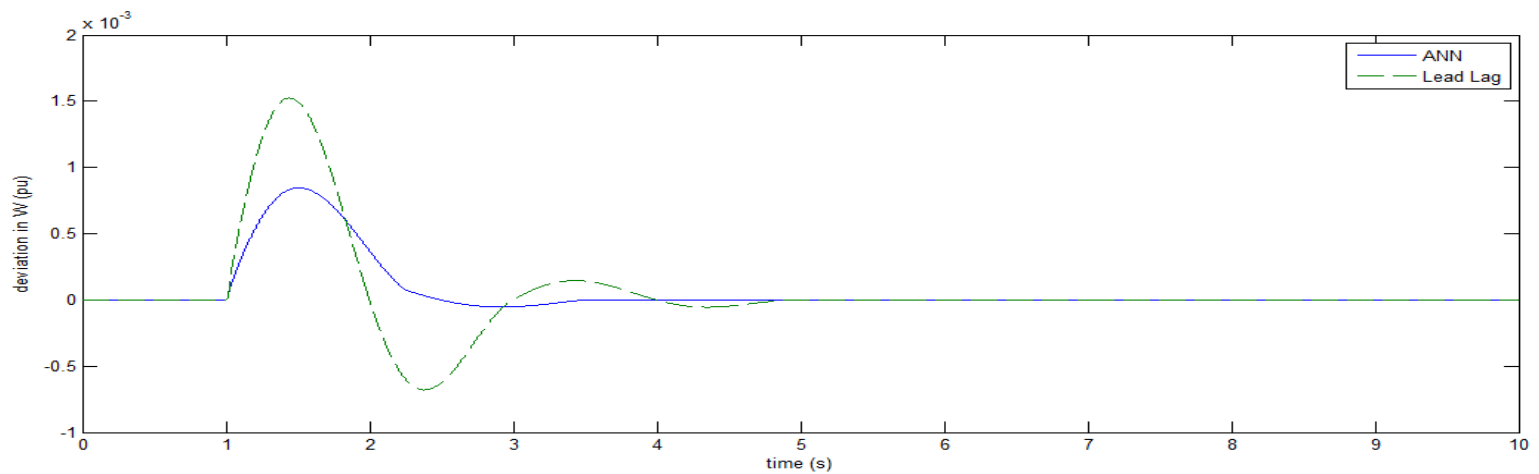

Fig 5: Angular velocity deviation during step change in mechanical input power for nominal load ( $\delta$ e Controller)

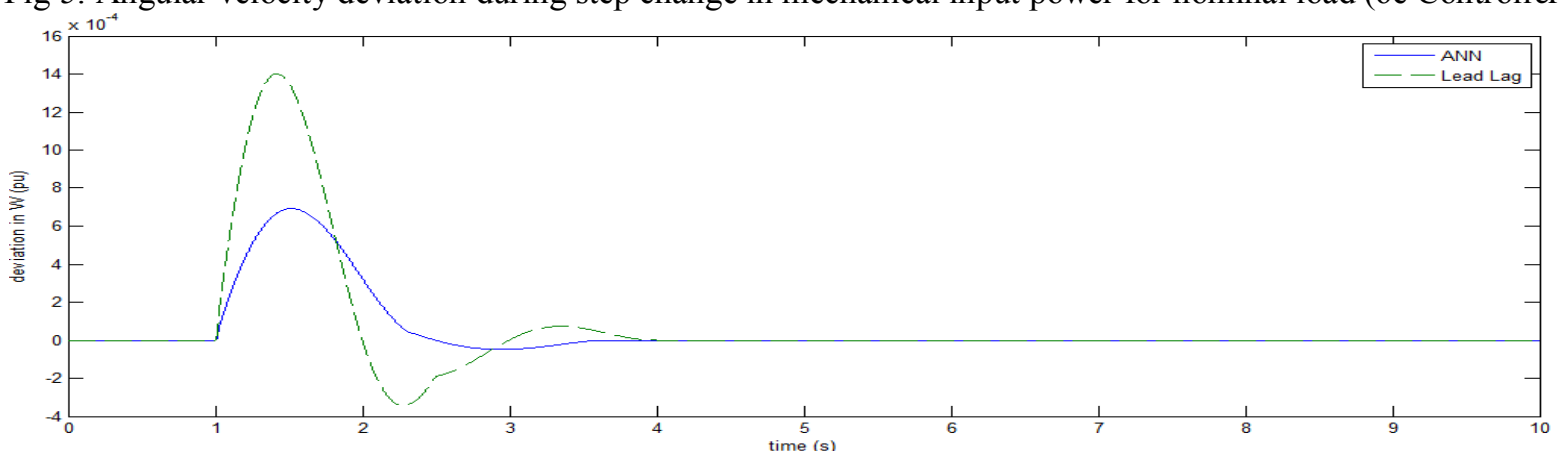

Fig 6: Angular velocity deviation during step change in mechanical input power for nominal load $\left(\mathrm{m}_{\mathrm{b}}\right.$ Controller $)$

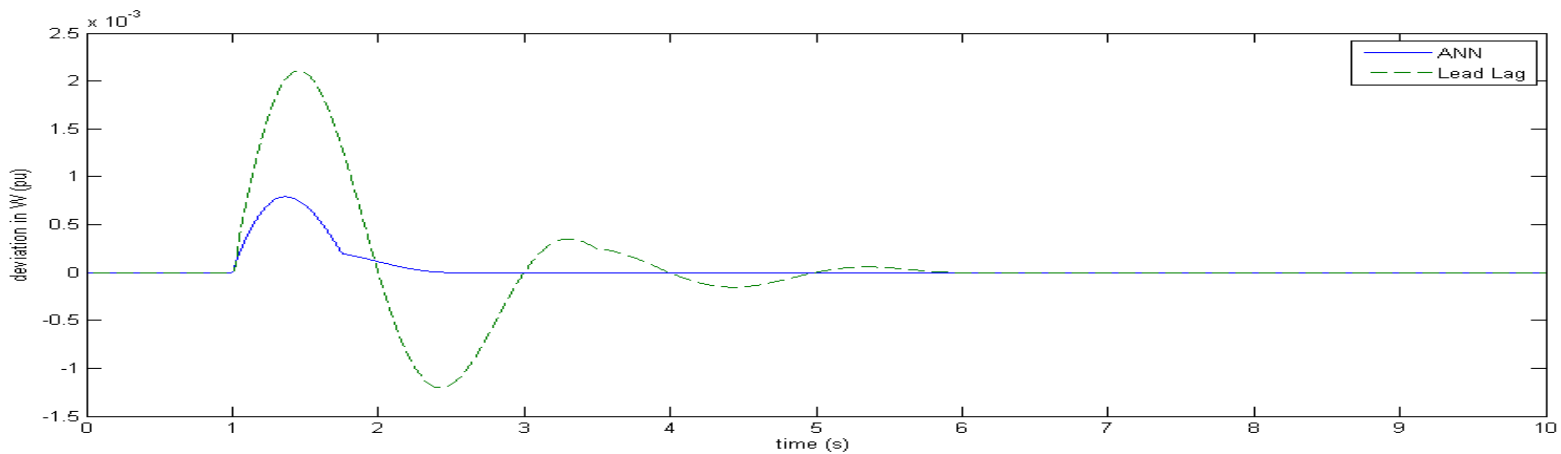

Fig.7 Angular velocity deviation during step change in mechanical input power for nominal load ( $\delta \mathrm{b}$ Controller)

As it can be seen from figures 3 to 7, lead-lag controller response is not as good as ANN damping controller response and also ANN damping controller decreases settling time. In addition maximum overshoot has decreased in comparison with lead-lag controller response.

In second case, simulations were performed when reference voltage has $5 \%$ increase $(\Delta \operatorname{Vref}=0.05 \mathrm{pu})$ at $\mathrm{t}=1 \mathrm{~s}$. Figure 8 demonstrates simulation result for step change in reference voltage, under nominal load and for $\delta b$ Controller.

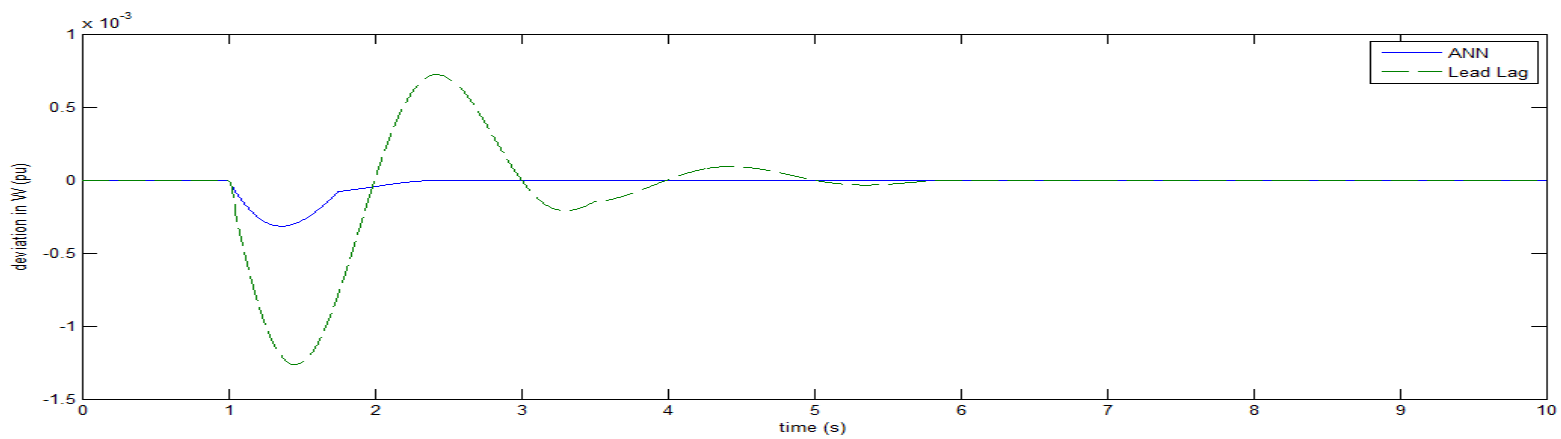

Fig. 8 Response of angular velocity for 5\% step change in reference voltage in the case of nominal load ( $\delta \mathrm{b}$ Controller)

www.iosrjen.org 
Consequently simulation results show that ANN damping controller successfully increases damping rate and decreases the amplitude of low frequency oscillations. Results comparison between conventional leadlag compensator and the proposed ANN damping controller for the UPFC indicates that the proposed ANN damping controller has less settling time and less overshoot in comparison with the conventional lead lag compensator.

\section{CONCLUSION}

With regard to UPFC capability in transient stability improvement and damping LFO of power systems, an adaptive ANN damping controller for UPFC was presented in this paper. The controller was designed for a single machine infinite bus system. Then simulation results for the system including ANN damping controller were compared with simulation results for the system including conventional lead-lag controller. Simulations were performed for different kinds of loads. Comparison showed that the proposed adaptive ANN damping controller has good ability to reduce settling time and reduce amplitude of LFO.

\section{APPENDIX}

Generator: $\mathrm{M}=2 \mathrm{H}=8.0 \mathrm{MJ} / \mathrm{MVA}, \mathrm{D}=0.0, \quad \mathrm{~T}_{\mathrm{do}}=5.044 \mathrm{~s}, \mathrm{X}_{\mathrm{d}}=1.0 \mathrm{pu}, \mathrm{X}_{\mathrm{q}}=0.6 \mathrm{pu}, \mathrm{X}_{\mathrm{d}}{ }_{\mathrm{d}}=0.3 \mathrm{pu}$

Exciter (IEEE Type ST1): $\mathrm{K}_{\mathrm{A}}=100, \mathrm{~T}_{\mathrm{A}}=0.01 \mathrm{~s}$

Reactances: $\mathrm{X}_{\mathrm{IE}}=0.1 \mathrm{pu}, \mathrm{X}_{\mathrm{E}}=\mathrm{X}_{\mathrm{B}}=0.1 \mathrm{pu} \mathrm{X}_{\mathrm{Bv}}=0.3 \mathrm{pu}, \mathrm{X}_{\mathrm{e}}=0.5 \mathrm{pu}$

Operation Condition: $\mathrm{P}_{\mathrm{e}}=0.8 \mathrm{pu}, \mathrm{V}_{\mathrm{t}}=1 \mathrm{pu}, \mathrm{V}_{\mathrm{b}}=1 \mathrm{pu}$

UPFC parameters: $\mathrm{m}_{\mathrm{E}}=0.4013, \mathrm{~m}_{\mathrm{B}}=0.0789, \delta_{\mathrm{E}}=-85.3478^{0} \delta_{\mathrm{B}}=-78.2174^{0}$

DC link: $\mathrm{V}_{\mathrm{dc}}=2 \mathrm{pu}, \mathrm{C}_{\mathrm{dc}}=1 \mathrm{pu}$

\section{REFERENCES}

[1] N. G. Hingorani and L. Gyugyi, Understanding FACTS: Concepts and Technology of Flexible AC Transmission System, IEEE Press, 2000 .

[2] H.F.Wang, F.J.Swift," A Unified Model for the Analysis of FACTS Devices in Damping Power System Oscillations Part I: Single-machine Infinite-bus Power Systems", IEEE Transactions on Power Delivery, Vol. 12, No. 2, April 1997, pp.941-946.

[3] L. Gyugyi, C.D. Schauder, S.L. Williams, T.R.Rietman, D.R. Torgerson, A. Edris, "The Unified Power Flow Controller: A New Approach to Power Transmission Control", IEEE Trans., 1995, pp. 1085-1097.

[4] Wolanki, F. D. Galiana, D. McGillis and G. Joos, "Mid-Point Sitting of FACTS Devices in Transmission Lines," IEEE Transactions on Power Delivery, vol. 12, No. 4, 1997, pp. 1717-1722.

[5] M. Noroozian, L. Angquist, M. Ghandari, and G. Anderson, "Use of UPFC for optimal power flow control", IEEE Trans. on Power Systems, vol. 12, no. 4, 1997, pp. 1629-1634.

[6] A Nabavi-Niaki and M R Iravani. 'Steady-state and Dynamic Models of Unified Power Flow Controller (UPFC) for Power System Studies.' IEEE Transactions on Power Systems, vol 11, 1996, p 1937.

[7] K S Smith, L Ran, J Penman. 'Dynamic Modelling of a Unified Power Flow Controller.' IEE Proceedings-C, vol 144, 1997 , pp.7.

[8] H F Wang. 'Damping Function of Unified Power Flow Controller.' IEE Proceedings-C, vol 146, no 1, January 1999, p 81

[9] H. F. Wang, F. J. Swift, "A Unified Model for the Analysis of FACTS Devices in Damping Power System Oscillations Part I: Single-machine Infinite-bus Power Systems," IEEE Transactions on Power Delivery, Vol.12, No. 2, April, 1997, pp. 941-946.

[10] P. Kundur,"Power System Stability and Control", McGraw-Hill.

[11] N. Tambey, M.L. Kothari, Damping of power system oscillations with unified power flow controller (UPFC),IEE Proc.-Gener. Transm.Distrib.,Vol. 150, No. 2, March 2009.

[12] Jang-Cheol Seo Seung-Il Moon Jong-Keun Park Jong-Woong Choe, "Design of a robust UPFC controller for enhancing the small signal stability inthe multi-machine power systems", IEEE Power Engineering Society Winter Meeting, 2001, pp. 352-356.

[13] Rahim, A.H.M.A. Al-Baiyat, S.A., "A robust damping controller design for a unified power flow controller", 39th International Universities Power Engineering Conference, 2004, pp. $265-269$

[14] Lo, K. L., T. T. Ma, J. Trecat, and M. Crappe,“A novel power control concept using ANN based multiple UPFCs scheme," Pro. EMPD '98, Singapore, pp. 570-575 (1998).

[15] Tsao-Tsung Ma "Multiple Upfe Damping Control Scheme Using Ann Coordinated Adaptive Controllers" Asian Journal of Control, Vol. 11, No. 5, pp. 489 502, September 2009.

[16] HSU, Y.Y. and JENG, L.H.: 'Analysis of torsional oscillations using an artificial neural network'. Presented at the IEEEiPES 1992 winter meeting. paper $92 \mathrm{WM} 003-4 \mathrm{EC}$ 